\title{
Efficiency Comparison between Brushless DC Motor and Brushless AC Motor Considering Driving Method and Machine Design
}

\author{
Masataka Miyamasu* Student Member, Kan Akatsu* Member
}

(Manuscript received March 17, 2012, revised Aug. 24, 2012)

\begin{abstract}
This paper describes an approach to achieve a high efficiency drive such a brushless AC (BLAC) drive by a Brushless DC (BLDC) drive. BLDC motors with an excited rectangular voltage for 120 electrical degrees per cycle are commonly used for low-cost applications of permanent magnet synchronous motors (PMSMs). This drive method yields low-order harmonic components in the current waveform. These harmonic components cause mechanical vibration and electrical losses. Therefore, a BLDC drive is not applicable to a sinusoidal back-EMF machine. However, with regard to the high-frequency loss caused by a pulse width modulation (PWM) carrier and a switching loss, the BLDC drive has the potential to achieve higher efficiency than the BLAC drive. This paper compares the overall efficiency, which includes the PWM carrier frequency loss, by using a coupling analysis between a finite element analysis (FEA) and a circuit simulator. Two surface-mounted PMSMs (SPMSMs) are tested. One has a sinusoidal back-EMF waveform (BLAC machine), and the other has a trapezoidal back-EMF waveform (BLDC machine). Both the driving methods of the BLDC drive and the BLAC drive are adapted to each machine and their efficiencies are compared by both simulations and experiments. The results show that the BLDC machine with a BLDC drive has higher efficiency than the BLAC machine with a BLAC drive.
\end{abstract}

Keywords: blushless AC (BLAC), blushless DC (BLDC), coupling analysis, efficiency, pulse width modulation (PWM), sinusoidal back-EMF, surface-mounted permanent magnet synchronous machine (SPMSM), trapezoidal back-EMF

\section{Introduction}

PMSMs have been widely used in a variety of applications in consumer electric appliances and industrial machines because of high efficiency and high power density. In general, these applications have to reduce costs. However, since an attention to global warming has been increased, it is required to reduce $\mathrm{CO}_{2}$ and also to suppress the energy consumption. Thus, low-cost and high efficiency motors are required.

PMSMs are classified into two categories. One is a brushless AC machine (BLAC) which has the sinusoidal backEMF and the other is a brushless DC machine (BLDC) which has the trapezoidal back-EMF. Usual the BLAC machine is excited by the sinusoidal waveform current with 180 electrical degree (BLAC drive). Since this excitation scheme uses the vector control by 16 or 32 bit microcomputer with rotor position information by a position sensor, the microcomputer and the sensor make the drive high-costs. On the other hand, the BLDC machine is typically excited by the rectangular waveform current with 120 electrical degree (BLDC drive). This excitation scheme and algorithm are simpler than the BLAC drive. In addition, a low resolution position sensor can be used. However, a torque pulsation due to the low-order harmonic components is a serious issue. Therefore, recent majority subject of the investigations is the BLAC drive.

It is interesting that both the BLDC and the BLAC drives use same 3 phase voltage source inverter, a difference of the

* Shibaura Institute of Technology

3-7-5, Toyosu, Koto-ku, Tokyo 135-8548, Japan driving method produces the different characteristics, such as a torque pulsation, and dynamic characteristics. Previous researches have compared the BLDC with the BLAC drive and reported at the view points of the characteristics with fluxweakening region ${ }^{(1)(2)}$. However, the efficiency and the loss characteristics have not been discussed in these researches because PWM loss analysis is very difficult. On the other hand, the recent analysis techniques such as a coupling analysis and an iron loss analysis by FEA make a brief comparison of these losses possible ${ }^{(3)(4)}$. Then, it is important to recognize how the efficiency of the BLAC machine is high compared with the BLDC machine.

This paper firstly shows that the iron and the copper losses of both the BLDC machine and the BLAC machine which are excited by both the BLDC drive and the BLAC drive. PWM carrier frequency effect to the efficiency is especially pointed out. Some simulations are carried out under the actual driving condition by the coupling analysis at variable speed and DC-link voltage. Then a reason of the efficiency difference is found out. As a result, this paper shows that the efficiency of the BLDC machine which is excited by the BLDC drive has the highest efficiency under the typical high speed and high duty factor condition. Furthermore, the simulation results are verified by the experiments. From the consequences of the experiments, the efficiency of the BLDC machine which is operated by the BLDC drive has the highest efficiency under all speed regions when the inverter losses are taken into account. 

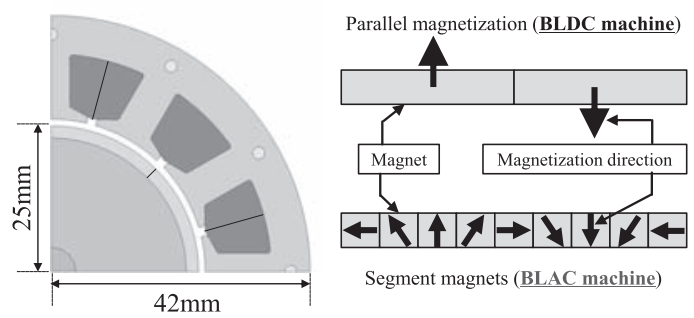

Fig. 1. Motor structure and magnetization methods

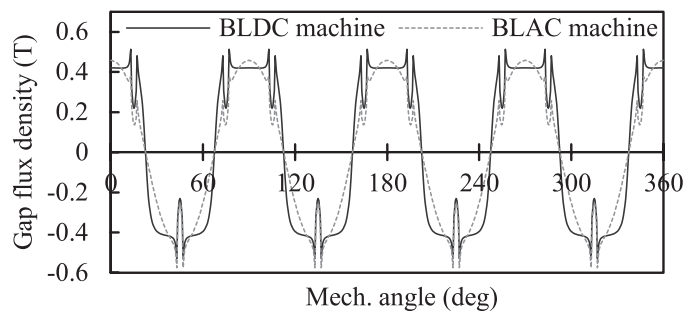

Fig. 2. Distributions of the air gap flux density
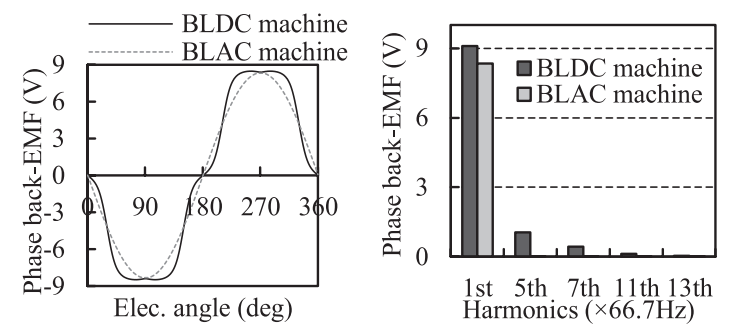

Fig. 3. Phase back-EMFs and FFT results (1000 rpm)

\section{Structure and No load Characteristic Compar- ison between BLDC Machine and BLAC Ma- chine}

In this instance, we compare the BLDC machine with the BLAC machine by FEA because they have different backEMF waveforms. A Surface-mounted PMSM (SPMSM) is used for the simulation motor models and magnetize directions are changed to realize each the BLDC machine and the BLAC machine. Fig. 1 shows a motor structure and the magnetization methods. These machines are concentrated windings and use same magnet material. In other words, the magnets have same the maximum energy product. The magnetize direction of the BLAC machine is specially arranged for the sinusoidal air gap flux density in Fig. 2 to minimize an effect of the stator spatial harmonics ${ }^{(5)}$. However, this magnetize method requires complex structure, it increases costs and it results to decrease total magnet flux linkage in the air gap.

For the BLDC machine, the magnet with parallel magnetization is used. This machine has the air gap flux density with the trapezoidal distribution. Although the back-EMF waveforms which are shown in Fig. 3 have same peak value, the BLDC machine has higher fundamental back-EMF than it of the BLAC machine. Therefore, the BLDC machine with trapezoidal back-EMF waveform has high $d$-axis linkage magnet flux.

Adding that, the harmonics in the trapezoidal back-EMF waveform can be effectively used by the harmonics of the BLDC drive because appropriate phase combination for the current and the back-EMF harmonics generates harmonic
Table 1. Simulation motors specifications

\begin{tabular}{|l|c|c|}
\hline & BLDC machine & BLAC machine \\
\hline Magnetization direction & Parallel & Segments (Fig. 1) \\
\hline Back-EMF waveform & Trapezoidal & Sinusoidal \\
\hline$d$-axis linkage magnet flux $(\mathrm{mWb})$ & $26.7(-)$ & $24.4(-8.6 \%)$ \\
\hline Peak back-EMF $\left(\mathrm{V}_{\mathrm{pk}}\right.$, 1000rpm) & \multicolumn{2}{|c|}{8.4} \\
\hline Number of poles & \multicolumn{2}{|c|}{8} \\
\hline Number of slots & \multicolumn{2}{|c|}{12} \\
\hline Gap length (mm) & \multicolumn{2}{|c|}{22} \\
\hline Stack length $(\mathrm{mm})$ & 0.78 \\
\hline Remanence flux density $(\mathrm{T})$ & 420 \\
\hline Coercive force $(\mathrm{kA} / \mathrm{m})$ & \multicolumn{2}{|c|}{1.1} \\
\hline Phase resistance $(\mathrm{Ohm})$ & \multicolumn{2}{|c|}{} \\
\hline
\end{tabular}

torque $^{(6)}$. Each simulation motor specifications are shown in Table 1.

\section{Comparison of BLDC Drive and BLAC Drive without harmonics due to PWM carrier}

In this section, we discuss about a comparison of the BLDC drive and the BLAC drive by the coupling analysis between the FEA and a circuit simulator. In general, the current waveform of the BLDC drive includes much harmonics than it of the BLAC drive since the rectangular voltage waveform by the BLDC drive includes low-order harmonic components. Furthermore, the current and voltage harmonics increase motor losses. The motor losses are generally divided into a copper loss $w_{c}$, an iron loss $w_{i}$ and a mechanical loss $w_{m}$. Each equation of the cupper loss and the iron loss is shown as follows respectively,

$$
\begin{aligned}
& w_{c}=3 I_{e}^{2} R_{a} \ldots \ldots \ldots \ldots \\
& w_{i}=K_{e} f^{2} B_{m}^{2}+K_{h} f B_{m}^{2} .
\end{aligned}
$$

Where, $I_{e}$ is RMS phase current, $R_{a}$ is a phase resistance, $K_{e}$ is an eddy-current loss coefficient, $K_{h}$ is a hysteresis loss coefficient, $f$ is a frequency of each flux density, $B_{m}$ is an amplitude of each flux density. $K_{e}$ and $K_{h}$ are decided by the loss curve of the laminated steel core. The harmonic iron losses are also calculated in (2), the total iron loss is a sum of the iron losses includes harmonic components. Then, the iron losses of PMSMs are increased due to the harmonic components of the flux density.

The efficiency in which the mechanical loss is ignored can be shown as follow.

$$
\eta=\frac{P_{\text {out }}}{P_{\text {out }}+w_{c}+w_{i}} \times 100[\%]
$$

The output power $P_{\text {out }}$ is

$$
P_{\text {out }}=T_{m} \omega_{m} .
$$

Where, $T_{m}$ is average output torque, $\omega_{m}$ is an angular velocity. The average output torque by using SPMSM with the BLAC machine can be calculated by a following equation.

$$
T_{m}=p \psi_{d} i_{q}
$$

Where, $p$ is a number of pole pairs, $\psi_{d}$ is a d-axis linkage 


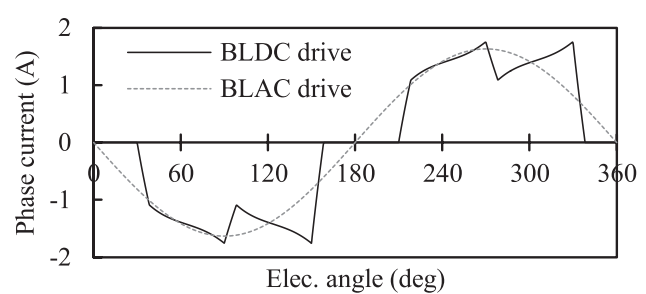

Fig. 4. Phase current waveforms $\left(I_{e}=1.15 \mathrm{~A}\right)$

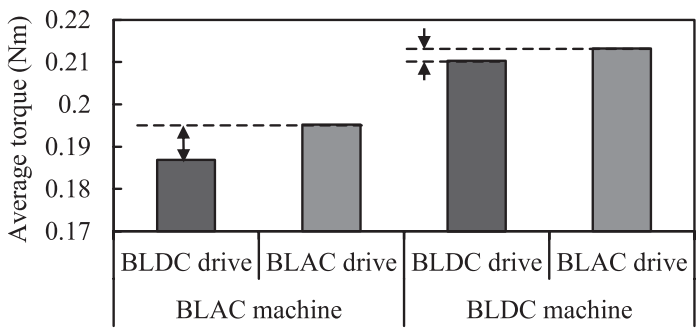

Fig. 5. Comparison of the analytical average torque

magnet flux, $i_{q}$ is a $q$-axis current. (5) indicates that the fundamental component of the current only contributes the average output torque of the sinusoidal back-EMF machine. Then, in an equal current RMS condition, the iron loss and the copper loss of the BLAC machine applied by the BLDC drive become higher than the losses by the BLAC drive because the BLDC drive induces the current and voltage harmonics. On the other hand, in the BLDC machine, these harmonics by the BLDC drive are available as the output torque. However, calculating the harmonic torque of the BLDC drive is difficult. Therefore, the comparison of the BLAC drive and the BLDC drive uses the average output torque calculated with the coupling analysis between the FEA and the circuit simulator.

Fig. 4 shows the phase current waveforms used in the coupling analysis. This simulation uses the BLAC machine and the BLDC machine applied the BLDC drive and the BLAC drive under the condition of the equal current RMS. These conditions set a constant copper loss at the all conditions. The comparison of the analytical average output torque in Fig. 5 describes that the BLDC drive using the BLAC machine has lower average torque compared with the BLAC drive using the BLAC machine at the same RMS current condition because only fundamental component of the phase current of the BLDC drive can contribute to generate torque for the BLAC machine. As a result, undesirable harmonics lead to the copper loss. In case the machine is changed from the BLAC machine to the BLDC machine for the BLDC drive, the difference of the average output torque is improved. This is because the BLDC drive can use the harmonic torque when the trapezoidal phase back-EMF and the rectangular current harmonics exactly interlace each other. In other words, the BLDC drive can use the torque due to the harmonics in addition to the torque of the fundamental component.

Fig. 6 shows a comparison of the analytical iron loss under the equal current RMS and the variable speed conditions. In both the hysteresis loss and the eddy-current loss, the BLDC machine generates much iron loss since the air gap flux density of this machine contains much low-order harmonic components than it of the BLAC machine. The BLDC drive also
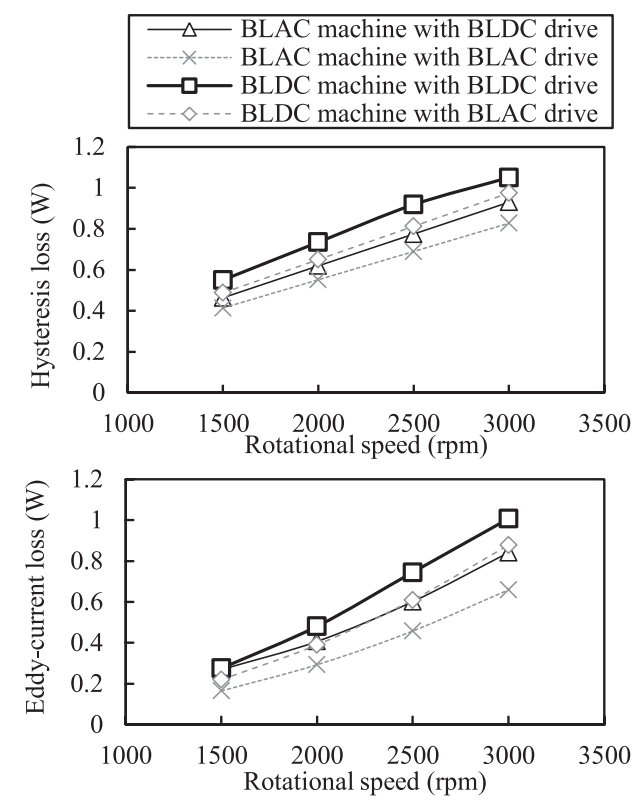

Fig. 6. Comparison of the analytical iron loss

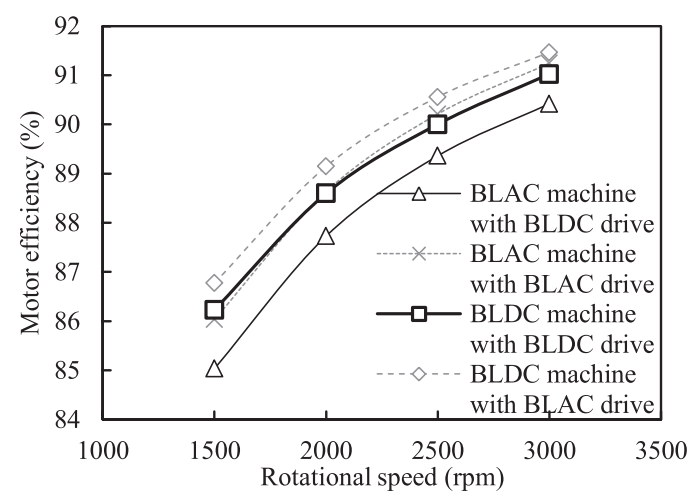

Fig. 7. Comparison of the analytical motor efficiency

has higher iron loss than it with the BLAC drive because of the distorted current waveform in Fig. 4.

Fig. 7 shows the calculated efficiencies by using (4). The efficiency of the BLDC machine is higher than it of the BLAC machine because of the difference of $d$-axis linkage magnet flux. The increase of it improves the average output torque. Both machines with the BLAC drive can achieve higher efficiency compared with them with the BLDC drive. This result shows that the ideal sinusoidal current excitation is superior to rectangular voltage excitation in this case because this sinusoidal excitation minimizes the copper loss and iron losses. However, the ideal current excitation is difficult in the actual motor system due to the inverter PWM carrier effect. The following section considers the comparison of the efficiency including PWM carrier effect.

\section{Comparison of BLDC Drive and BLAC Drive considering PWM Carrier Effect}

This section discusses the copper loss, the iron loss and the efficiency which focuses on PWM carrier effect. The BLDC drive and the BLAC drive can control the output voltage by inverter switches. On the other hand, PWM carrier effect in each drive methods is different ${ }^{(7)}$. At first, we consider the switching characteristics of the BLDC drive and the BLAC 


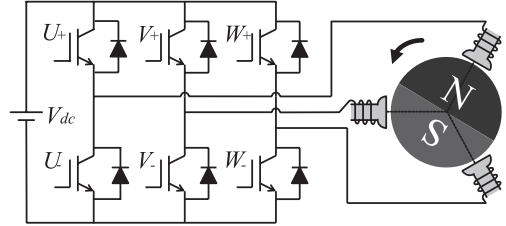

Fig. 8. Simple equivalent circuit of PMSM
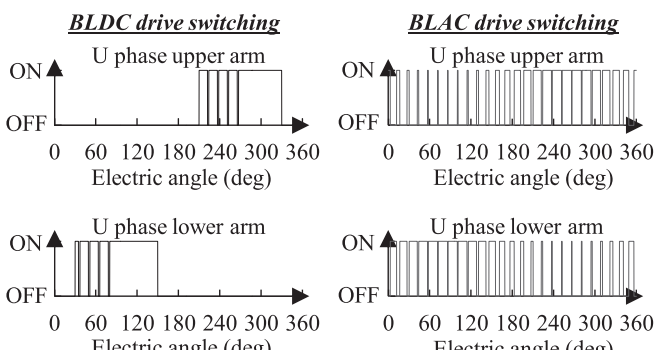

Fig. 9. Comparison of each switching waveforms

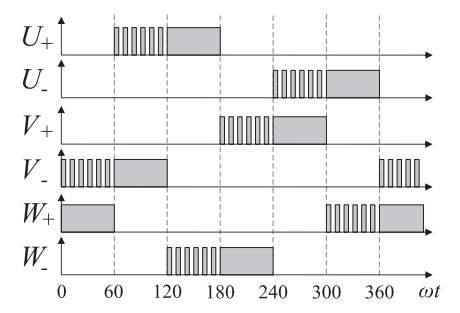

Fig. 10. Voltage control technique by BLDC drive

drive.

Fig. 8 shows a simple equivalent circuit of PMSM and Fig. 9 shows $U$ phase switching waveforms in the inverter under the equal carrier frequency condition. Every solid state switches of the inverter with the BLAC drive is switched by the carrier frequency. On the other hand, as shown in Fig. 10 which shows the voltage control technique by the BLDC drive, the BLDC drive simultaneously turns on two solid state switches. In addition, only one of the switches is switched by the carrier frequency. This fact indicates that the BLDC drive will have higher inverter efficiency than it with the BLAC drive because of its lower switching loss.

Furthermore, the BLDC drive does not need a dead time of the inverter, since it has enough periods between the upper arm and the lower arm switching in the inverter. The dead time causes the distortion and reduction of the actual output voltage against to the reference value because it delays turn on time of the switches compared to the reference signal ${ }^{(8)}$. The distorted voltage leads to increase the iron loss, and the reduction of output voltage which relates to the maximum output voltage.

In general, the fundamental component of the maximum output phase voltage by the BLAC drive can be described by the following equation.

$$
V_{B L A C}=\frac{V_{d c}}{2}
$$

On the other hand, the fundamental component of the maximum output phase voltage by the BLDC drive is

$$
V_{B L D C}=\frac{V_{d c} \sqrt{3}}{\pi} .
$$

Table 2. Conditions of the comparison

\begin{tabular}{|l|c|c|}
\hline & Conditon I & Condition II \\
\hline Tested machine & BLAC & BLAC, BLDC \\
\hline Phase current $I_{e}($ Arms $)$ & \multicolumn{2}{|c|}{1.15} \\
\hline DC link voltage $V_{d c}(\mathrm{~V})$ & Variable & 60 \\
\hline Rotational speed $N(\mathrm{rpm})$ & 2500 & Variable \\
\hline Carrier frequency $f_{c}(\mathrm{kHz})$ & \multicolumn{2}{|c|}{5} \\
\hline
\end{tabular}

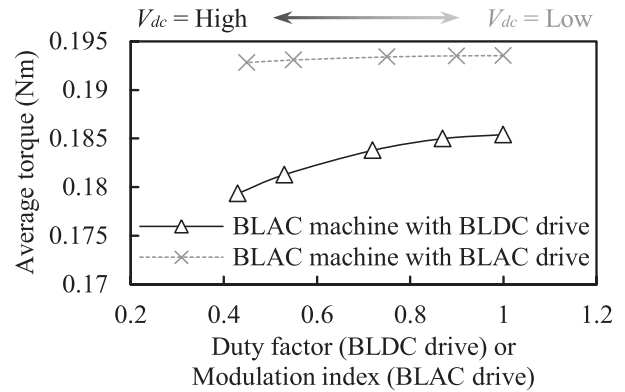

Fig. 11. Average torque characteristics under the same copper loss condition (Condition I)

Due to absence of the dead time, the BLDC drive inverter output voltage is more efficient than it of the BLAC drive.

The BLDC drive method for PMSMs has various voltage control techniques ${ }^{(9)}$ with three phase inverter. Usually the chopper control is used to control average voltage. In this paper, an alternative chopper control ${ }^{(10)}$ which is shown in Fig. 10 is used. Solid state switches on the inverter are turned on and off at a chopper frequency, the upper arm and the lower arm switches are alternately chopped at 60 electrical degree period. This control method has a characteristic without reversal DC-link currents ${ }^{(11)}$ and low torque pulsation ${ }^{(12)}$ compared to another general PWM techniques. It is important to consider PWM carrier effect because these PWM controls almost distort the voltage and current by the carrier frequency harmonic components.

Table 2 shows parameters which are used in this simulation. We investigate two conditions because a genuine comparison is difficult by only one condition since the BLAC and the BLDC machines which applied the BLAC and the BLDC drives have different characteristics. These conditions set a constant copper loss.

4.1 Arbitrary DC Link Voltage Condition (Condition I) In this condition I, we discuss about the characteristics of the average output torque depends on DC link voltage to define an optimal DC link voltage for the BLDC drive. The average torque characteristics under the condition I are shown in Fig. 11. A reason that this simulation does not apply to the BLDC machine is the effect of DC link voltage to the torque constant is not so different between in the BLDC machine and the BLAC machine. As shown in Fig. 11, DC link voltage changes a duty factor and a modulation index. Thus, a horizontal axis indicates these factors. The average torque is also increased as the duty factor is increased for the BLDC drive. On the other hand, the average torque of the BLAC drive is not affected of the modulation index.

Fig. 12 shows the phase current waveforms by the BLDC drive under the condition I and Fig. 13 shows their FFT result. 


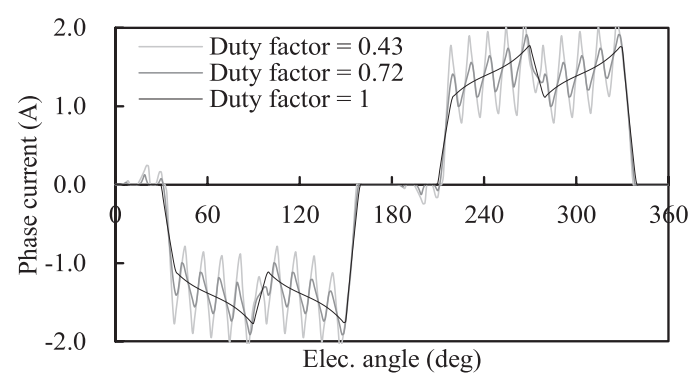

Fig. 12. Phase current waveforms by BLDC drive (Condition I)

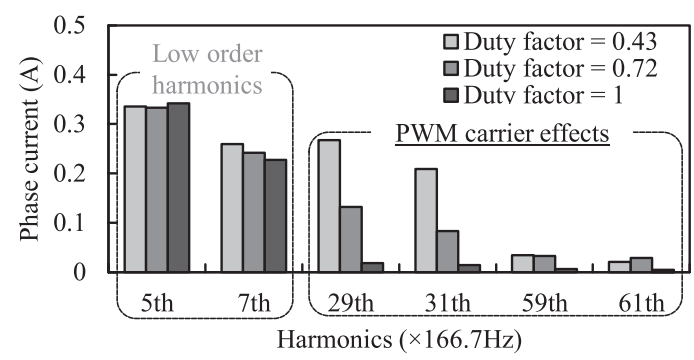

Fig. 13. FFT result by BLDC drive (Condition I)

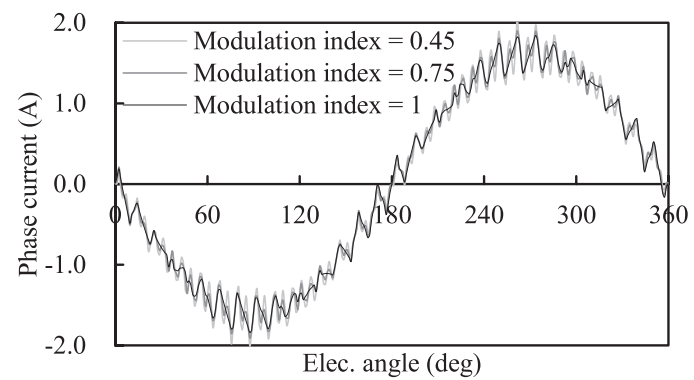

Fig. 14. Phase current waveforms by BLAC drive (Condition I)

The BLDC drive can suppress PWM carrier effect by increasing the duty factor. The current harmonic components due to PWM carrier effect do not contribute average output torque. Therefore, only the copper loss is increased as the duty factor is decreased, the BLDC drive is effective to decrease the copper loss in low DC link voltage and high speed region in which high duty factor is realized. On the other hand, as shown in Fig. 11, the BLAC drive almost remains average output torque against the variable voltage.

Fig. 14 shows phase current waveforms by the BLAC drive under the condition I and Fig. 15 shows their FFT result. The BLAC drive has little low order harmonic components. However, the BLAC drive with the change of DC link voltage scarcely suppresses the harmonic components due to PWM carrier effect.

4.2 Arbitrary Speed Condition (Condition II) In this condition II, we considered an iron loss separation of the BLDC drive and the BLAC drive. Fig. 18 shows results of the iron loss analysis including PWM carrier effect and Figs. 16 and 17 show the hysteresis loss and the eddy-current loss respectively. The BLDC drive generates much hysteresis loss since the current waveform of this drive contains much low-order harmonic components than it of the BLAC drive. On the other hand, the BLAC drive generates much eddycurrent loss. These results indicate that the BLAC drive is

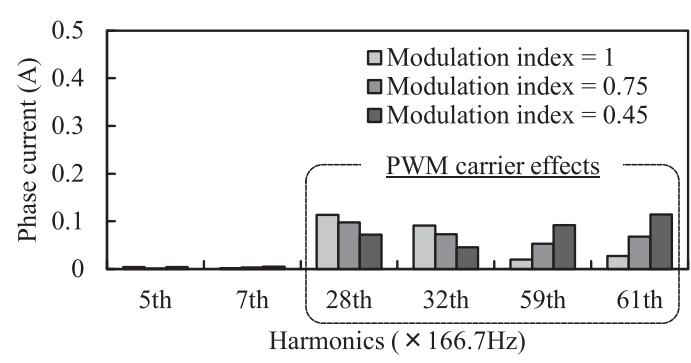

Fig. 15. FFT result by BLAC drive (Condition I)

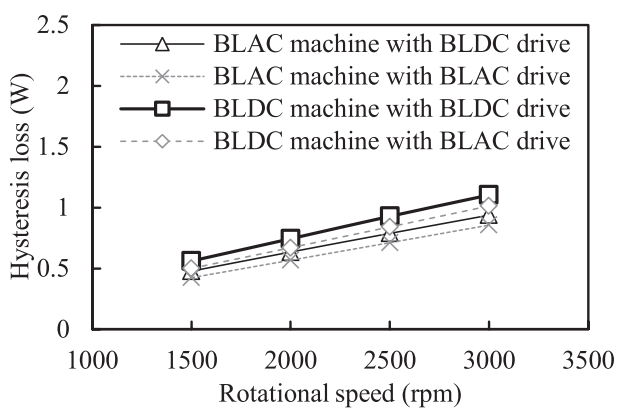

Fig. 16. Comparison of the analytical hysteresis loss (Condition II)

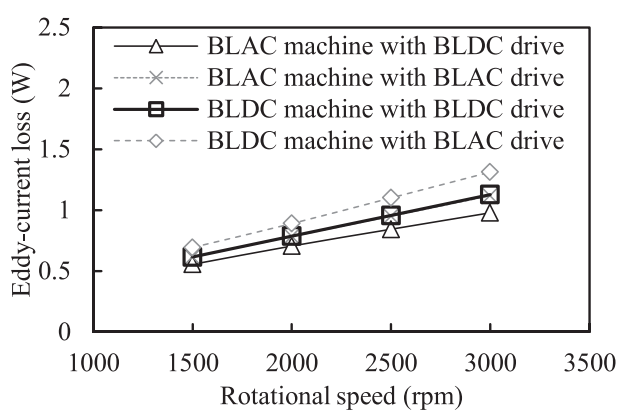

Fig. 17. Comparison of the analytical eddy-current loss (Condition II)

more sensitive to PWM carrier effect than the BLDC drive. The reason is that if PWM carrier effect is intense, the eddycurrent loss is increasing as shown in (2) since the carrier frequency is higher than low-order harmonics frequency which is contained in phase current by the BLDC drive. Thus, in low speed region, the total iron loss in Fig. 18 at the same machine under the same condition is approximately equal by a trade-off between the eddy-current loss and the hysteresis loss. In addition, because the BLDC drive with the high duty factor can suppress a lot of harmonic components due to PWM carrier frequency, the total iron loss by the BLDC drive is lower than it of the BLAC drive in high speed region.

From the above discussions, it is described that the BLDC drive has some advantages for the BLAC drive as follows.

(a) The BLDC drive can use the harmonic components of the magnet flux in air gap by the proper harmonics phase.

(b) The BLDC drive can control average voltage with the minimum switching under the equal carrier frequency condition.

(c) The BLDC drive suppresses PWM carrier effect to the copper and iron losses under the high duty factor condition. 


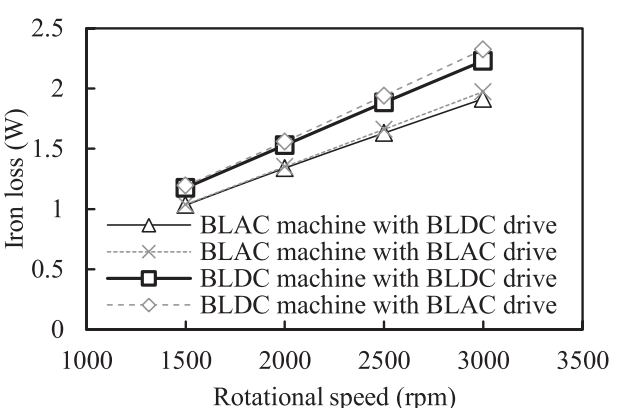

Fig. 18. Comparison of the total iron loss (Condition II)

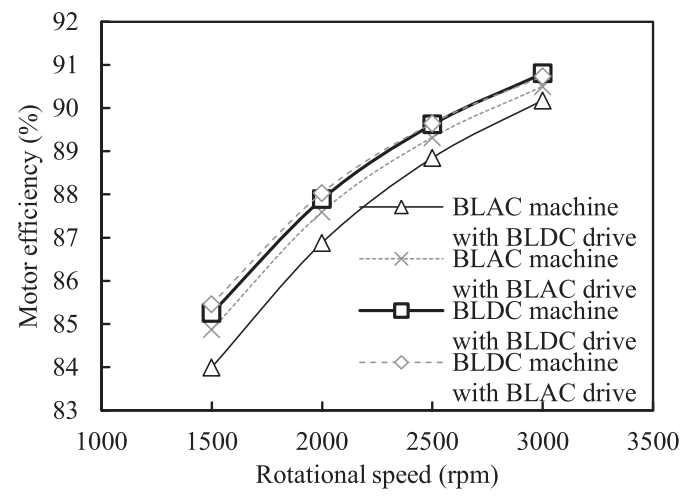

Fig. 19. Comparison of the motor efficiency (Condition II)

The efficiencies of the BLAC machine and the BLDC machine applied the BLDC drive and the BLAC drive considering PWM carrier effect is shown in Fig. 19. A comparison between Fig. 7 and Fig. 19 can clear PWM carrier effect to the efficiency. A case of the BLAC machine with the BLAC drive has higher efficiency than same machine with the BLDC drive at every speed. However, the BLDC machine with the BLDC drive and same machine with the BLAC drive including PWM carrier effect have almost equal efficiency at high speed region. In addition, former analysis results do not take into account of the inverter loss, for example, the switching loss and the dead time effect. Therefore, the BLDC drive has a potential to higher efficiency in the total motor systems constituted PMSM and the inverter.

\section{Experimental Comparison and Verification}

In this section, the experimental results are shown to verify their performances which include the inverter loss. Tested machines are the BLAC machine and the BLDC machine which has the sinusoidal and trapezoidal phase back-EMFs respectively, and both the BLDC drive and the BLAC drive are applied to each machine. The test bed and the inverter are shown in Fig. 20. Table 3 shows the specifications of the tested motors. These machines consist of each of the two rotors and the same stator. Therefore, the stator structure is perfectly same. This stator has a concentrated winding. Fig. 21 shows measured phase back-EMF waveforms of each tested motor which has the sinusoidal and the trapezoidal shape back-EMF respectively. The tested machine and the simulation model are same in size. On the other hand, the amplitude of back-EMF is different because magnetization to generate equal amplitude is difficult from the manufacturing

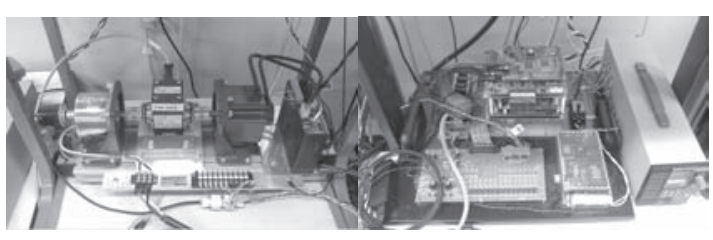

Fig. 20. Experimental equipment

Table 3. Tested motors specifications

\begin{tabular}{|l|c|c|}
\hline & BLDC machine & BLAC machine \\
\hline Back-EMF waveform & Trapezoidal & Sinusoidal \\
\hline$d$-axis linkage magnet flux $(\mathrm{mWb})$ & $57.5(-)$ & $40.9(-28.9 \%)$ \\
\hline Number of poles & \multicolumn{2}{|c|}{8} \\
\hline Number of slots & \multicolumn{2}{|c|}{12} \\
\hline Gap length (mm) & \multicolumn{2}{|c|}{1} \\
\hline Stack length $(\mathrm{mm})$ & 22 \\
\hline Phase resistance $(\mathrm{Ohm})$ & 0.95 \\
\hline
\end{tabular}
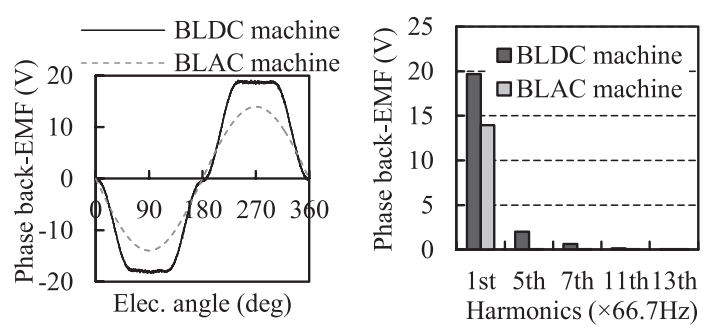

Fig. 21. Phase back-EMFs and FFT results (1000 rpm)

reason. Therefore, these experimental comparisons focus on the difference of the drive method applied for each machine. However, the influence of the amplitude difference can be analyzed from the simulation results because the fundamental component of back-EMF depends greatly on the output torque, the BLDC machine with same peak flux linkage to the BLAC machine is expected to have high torque and high efficiency by FEA results. Experimental condition compares variable speed and DC link voltage characteristics of the BLDC drive and the BLAC drive. This is the same condition with the simulation condition I and II which is shown in Table 2.

5.1 Experimental Condition of Arbitrary DC Link Voltage (Condition I) In Fig. 22, average output torque of the condition I which the BLDC drive and the BLAC drive are applied to the BLAC machine is shown. This result is the same tendency with the simulation results which are shown in Fig. 11. The high DC link voltage results the reduction of motor output torque of the BLDC drive. Since the efficiency of the motor depends on the output torque, DC link voltage becomes an important factor in order to decide the motor efficiency in case the BLDC drive is applied. In the following discussion, we add an additional experiment condition to research a relationship between DC link voltage and the efficiency.

5.2 Experiment to Verify DC Link Voltage Relativity Effects to the Efficiency (Additional Condition) An additional condition is applied to the BLDC machine with each drive method when DC link voltage is set as $60 \mathrm{~V}$ and $100 \mathrm{~V}$. Table 4 shows a condition of this comparative experiment. 


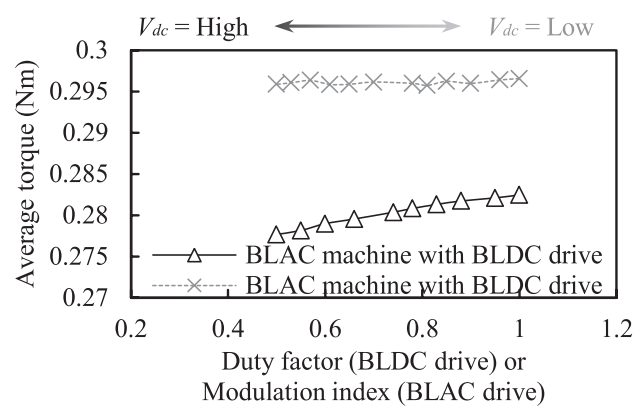

Fig. 22. Experimental results of the average torque characteristics (Condition I)

Table 4. Additional condition of the comparison

\begin{tabular}{|l|c|}
\hline & Additional condition \\
\hline Tested machine & BLDC \\
\hline Phase current $I_{e}($ Arms $)$ & 1.15 \\
\hline DC link voltage $V_{d c}(\mathrm{~V})$ & 60 and 100 \\
\hline Rotational speed $N(\mathrm{rpm})$ & Variable \\
\hline Carrier frequency $f_{c}(\mathrm{kHz})$ & 5 \\
\hline
\end{tabular}

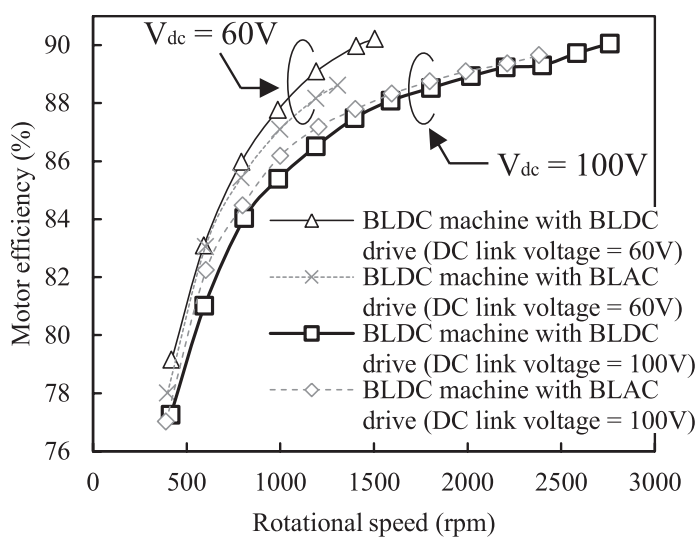

Fig. 23. Experimental results of the comparison of the motor efficiency (Additional condition)

Rotational speed is increased until the modulation index or the duty factor reaches one, since the maximum rotational speed is decided by these factors. If the inverter has the high maximum output voltage, the maximum rotational speed is generally high. Therefore, the maximum rotational speed is different by each driving method and each DC link voltage.

In case of $60 \mathrm{~V}$ DC link voltage, the efficiency of the BLDC drive is higher than it of the BLAC drive. On the other hand, in case of the $100 \mathrm{~V} \mathrm{DC}$ link voltage, the efficiency of the BLDC drive is lower than it of the BLAC drive. From these results, it is obvious that the BLDC drive effectively suppress the PWM carrier effect by low voltage and high duty. It is clear that the BLDC drive should be used under the condition of the low DC link voltage. If the efficiency of each driving point is measured or estimated, it can be found an advantageous driving point compared to the BLAC drive. However, something like the experiment system or the coupling analysis must be used in order to obtain accurate efficiency considering PWM carrier effects. The theoretical superior value of DC link voltage is difficult to find by using the numerical calculation.

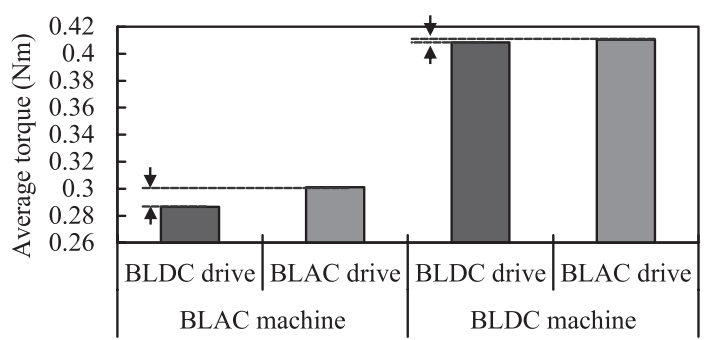

Fig. 24. Experimental results of the comparison of the average torque at the $1000 \mathrm{rpm}$ (Condition II)

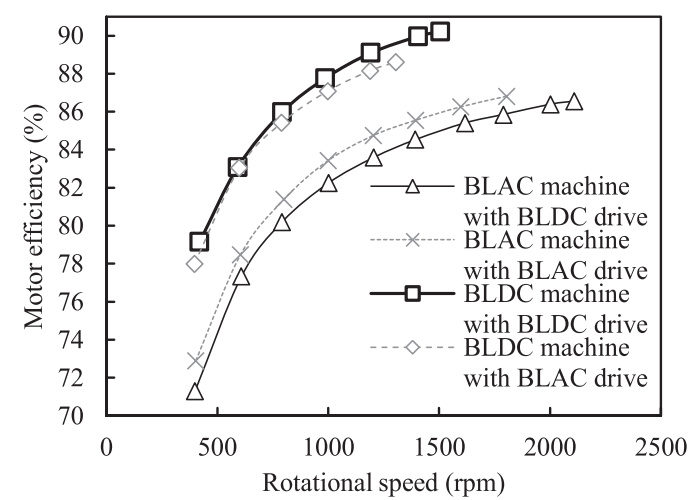

Fig. 25. Experimental results of the comparison of the motor efficiency (Condition II)

\subsection{Experimental Condition of Arbitrary Speed (Con-} dition II) The average output torque at $1000 \mathrm{rpm}$ of the BLDC machine with the BLDC drive is higher than it of the BLAC machine with the BLDC drive and the torque is as high as it of the BLDC machine with the BLAC drive which is shown in Fig. 24. Fig. 25 shows measured efficiency of tested motors at the condition II. Where, the different peak amplitude of back-EMF causes a difference of the maximum rotational speed of each machine. The BLDC machine has lower maximum rotational speed compared with the BLAC machine. However, the BLDC machine with the BLDC drive has the highest efficiency at all speed region. These experimental results are the same tendency with simulation results which are shown in Fig. 5 and Fig. 19.

Fig. 26 shows the inverter efficiency when the BLDC drive and the BLAC drive apply to the BLAC machine and the BLDC machine at the condition II. As expected, the inverter efficiency of the BLDC drive is higher than it of the BLAC drive under the all speed region. Thus, it is experimentally verified that the BLDC drive has the low inverter loss, i.e., low switching loss driving method.

The experimental results in Fig. 25 and Fig. 26 are used to estimate total efficiency in Fig. 27. The BLDC machine with the BLDC drive has the highest total efficiency in these machines and drive combinations.

The machines used in this experiment have different backEMF amplitude with the one used in the simulation. Therefore, even though the experiment is performed using the same examination condition, the maximum rotational speed, output torque and motor efficiency are slightly different. However, these experiment results can be considered as a proper because the experimental results have similar tendency with the simulation results. 


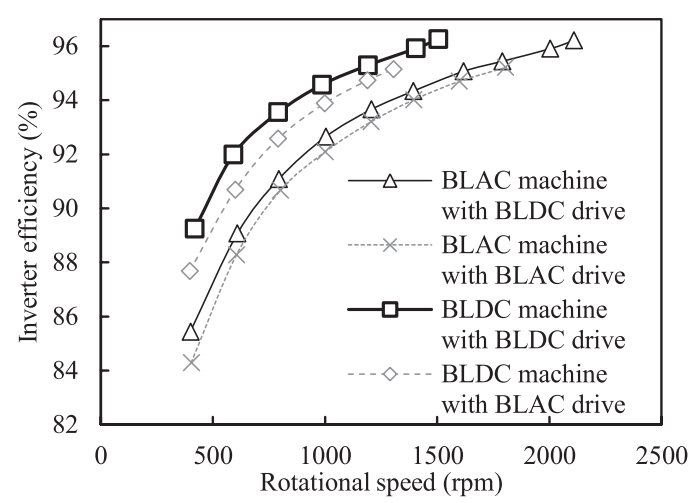

Fig. 26. Experimental results of the comparison of the inverter efficiency (Condition II)

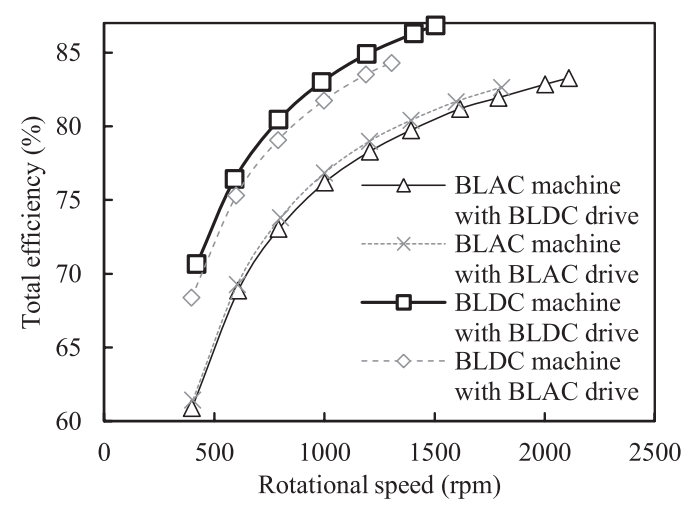

Fig. 27. Experimental results of the comparison of the total efficiency (Condition II)

\section{Conclusion}

This paper calculated the efficiency of two types of machines, the sinusoidal back-EMF machine (BLAC machine) and the trapezoidal back-EMF machine (BLDC machine), each machine was driven by the two types of drives, the BLAC drive and the BLDC drive. To calculate PWM loss of each machine, the coupling analysis method between FEA and the circuit simulator was used.

The BLDC machine can have a higher fundamental magnet flux component than the BLAC machine when the same maximum energy product magnet is used under the same stator and rotor geometry. Simulation results showed that off course the BLAC drive was better for the BLAC machine. However, for the BLDC machine, the BLDC drive achieved as high efficiency as the BLAC machine because of utilizing the harmonics. These results indicate that the BLDC machine with the BLDC drive has a potential to realize high efficiency and low-costs.

The experimental results show that the BLDC drive was effective driving method since it can easily decrease the inverter loss compared to the loss of the BLAC drive. Additionally, high duty factor region i.e. low DC link voltage optimizes the BLDC drive. Therefore, the BLDC machine with the BLDC drive has the highest total efficiency in these machines and drives combination in the experiment.

These results give a considerable choice of select the machine and its driving method to achieve high efficiency and cost reduction.

\section{References}

( 1 ) Y.F. Shi, Z.Q. Zhu, and D. Howe: "Torque-speed characteristics of interiormagnet machine in brushless AC and DC modes, with particular reference to their flux-weakening performance”, Proc. Int. Power Electronics and Motion Control Conf. (IPEMC), Vol.3, pp.1-5 (2006)

( 2 ) Z.Q. Zhu, J.X. Shen, and D. Howe: "Flux-weakening characteristics of trapezoidal back-emf machines in brushless DC and AC modes", Proc. Int. Power Electronics and Motion Control Conf. (IPEMC), Vol.2, pp.1-5 (2006)

( 3 ) K. Narita, T. Yamada, Y. Sakashita, and K. Akatsu: "Iron Loss Calculation of PM Motor by Coupling Analysis between Magnetic Field Simulator and Control Simulator", Electrical Machines and Systems (ICEMS 2008), pp.33013306 (2008)

( 4 ) K. Akatsu and R.D. Lorenz: "Comparing Coupled Analysis with Experimental Results for an Interior PM Machine”, IEEE Trans. Ind. Applicat., Vol.45, No.1 (2009)

( 5 ) K. Yoshida, K. Kesamaru, and S. Sano: "Cogging Torque and Rotor Core Reduction of Segment Surface-Mounted-PM Motor", IEEE Trans. Ind. Applicat., Vol.124, No.1 (2004)

( 6 ) P.L. Chapman, S.D. Sudhoff, and C.A. Whitcomb: "Optimal current control strategies for surface-mounted permanent-magnet synchronous machine drives", IEEE Trans. on Energy Conversion, Vol.14, No.4, pp.1043-1050 (1999)

( 7 ) R. Liu, C. Mi, and W. Gao: "Modeling of Eddy Current Losses of Electrical Machines and Transformers Operated by Pulsewidth-Modulated Inverters", IEEE Trans. on Magnetics, Vol.44, No.8 (2008)

( 8 ) R.C. Dodson, P.D. Evans, H. Tabatabaei, and S.C. Harley: "Compensating for dead time degradation of PWM inverter waveforms", Proc. Inst. Elect. Eng., Vol.137, No.2 (1990)

(9) Y.S. Lai and Y.K. Lin: "Quicken the pulse", IEEE Industry Applications Magazine, Vol.14, No.5, pp.34-44 (2008)

(10) S. Ogasawara and H. Akagi: "An approach to position sensorless drive for brushless dc motors", IEEE Trans. Ind. Applicat., Vol.27, No.5, pp.928-933 (1991)

(11) Y.S. Lai, F.S. Shyu, and Y.K. Lin: "Novel PWM technique without causing reversal DC-link current for brushless DC motor drives with bootstrap driver", in Proc. of IEEE IAS, Vol.3, pp.2182-2188 (2005)

(12) R. Carlson, M.L. Mazenc, and J.C.S. Fagundes: "Analysis of torque ripple due to phase commutation in brushless DC machines", IEEE Trans. Ind. Applicat., Vol.28, No.3, pp.632-638 (1992)

Masataka Miyamasu (Student Member) was born in Kanagawa pre-

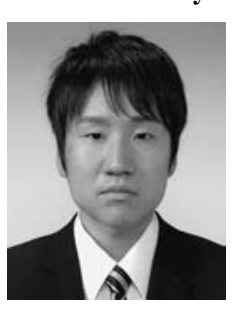
fecture, Japan in September 8, 1988. He received B.S. degree in electrical engineering from Shibaura institute of technology, Tokyo, Japan, in 2011. His research interests are control and design of the permanent magnet synchronous motor. Mr. Miyamasu is a student member of the IEEE.

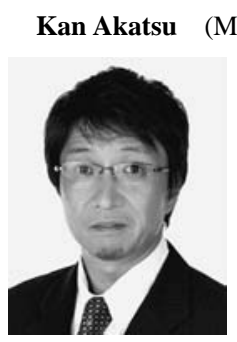

Member) received B.S., M.S., and Ph.D degrees in electrical engineering from Yokohama National University, Yokohama, Japan, in 1995, 1997, 2000 respectively. He joined Nissan Research Center, Yokosuka, Japan, in 2000, he contributed to the design and analysis of the new concept permanent magnet machines. In 2003, he joined the department of Electrical and Electric Engineering at Tokyo University of Agriculture and Technology, Tokyo, Japan, as an assistant professor. From 2005 to 2007, he is a JSPS Postdoctoral Fellowship for Research Abroad, visiting professor in WEMPEC (Wisconsin Electric Machines and Power Electronics Consortium), University of Wisconsin-Madison. From 2009, he is an associate professor in Shibaura Institute of Technology, Tokyo, Japan. His research interests are motor control, motor design and inverter control. Dr. Akatsu is a member of the IEEE PELS, IAS, IE and IEE of Japan. 